\title{
Patterns of disturbance and recovery in littoral rock pools: nonhierarchical competition and spatial variability in secondary succession
}

\author{
Lisandro Benedetti-Cecchi*, Francesco Cinelli \\ Dipartimento di Scienze dell'Ambiente e del Territorio, Università di Pisa, Via A. Volta 6, I-56126 Pisa, Italy
}

\begin{abstract}
Patterns of disturbance and recovery were investigated in algal-dominated littoral rock pools on the west coast of Italy from February 1991 to November 1993. The assemblage was a mosaic of canopyforming species interspersed amongst patches of turf-forming and encrusting algae. The effects of natural disturbance were investigated by monitoring the size distributions of patches of open space (mainly consisting of encrusting corallines and bare rock) in fixed plots over $2 \mathrm{yr}$. These plots were distributed in pools maintained at natural and reduced densities of herbivores. In both cases, the mean percentage of open space did not change greatly from February 1991 to February 1993, nor were there differences attributable to grazing by the end of the monitoring period. Shifts in size distributions of natural patches of open space occurred during the $2 y$ of observations. The area accounted for by large size-classes $\left(>1200 \mathrm{~cm}^{2}\right)$ increased in pools exposed to natural densities of herbivores and decreased in the others. However, grazers never affected size distributions significantly. Overall, results suggested that the provision of open space in this system was mainly due to physical disturbances. A multifactorial experiment was used to assess the effects of herbivores (natural vs reduced densities), size of patch $(17 \times 17 \mathrm{vs} 32 \times 32 \mathrm{~cm})$ and time of clearance (February vs August) on algal colonization in experimentally cleared plots. An additional experiment tested for the effects of algal turfs on the establishment of canopy-forming algae in pools where grazers had been removed. The results of the recolonization experiment indicated that herbivores, size of patches and time of clearance exerted important but variable effects on patterns of algal recolonization. Herbivores reduced but could not prevent algal recovery. Their effect was particularly evident for the algal turfs throughout the study, but it was not significant for Cystoseira spp. by the end of the experiment. There were significant size $x$ time of clearance interactions affecting patterns of algal colonization early in the study. The percent cover of turf-forming and canopy-forming plants was greater in the small plots produced in February 1991 than in the other treatments. These effects were more evident in pools exposed to natural densities of grazers and during the early stages of colonization. The results also suggested that competition among Cystoseira spp. and algal turfs was nonhierarchical, the outcome of the interaction depending primarily upon the relatıve density and life stage of the interacting organisms, rather than on their identity. This view was supported by the fact that established mats of algal turfs drastically inhibited the recruitment of Cystoseira, whilst no strong interaction occurred if recruitment by these species was synchronous. Thus, variability in the intensity and timing of colonization could have important effects for subsequent patterns of algal dominance in this system, but only when grazing was unimportant and algal colonization plentiful. Alternative models were formulated to explain spatial and temporal patterns in pools where these conditions did not occur
\end{abstract}

KEY WORDS: Disturbance - Spatial heterogeneity - Temporal heterogeneity Competitive herarchies Algae Herbivory Rock pools

\section{INTRODUCTION}

In many natural communities component organisms are distributed heterogeneously in space and time. Natural disturbance is considered as an important force

-E-mail: bencecc@discat.unipi.it affecting the organization of natural assemblages of species in space-limited systems (Sousa 1984a, Pickett \& White 1985). Disturbances range in intensity from catastrophes (sensu Harper 1977) to chronic events (Dethier 1984). The former ale lāinge-scâle cpisodic events mainly due to physical forces such as earthquakes or hurricanes (Heinselman 1973, Henry \& 
Swan 1974). The latter, either physical and biological, occur at smaller scales, are less destructive and supposedly act as mechanisms of natural selection (Sprugel 1976, Werner 1977, Paine 1979, Blau 1980, Suchanek 1981).

In space-limited systems, chronic disturbances may fragment the community into a mosaic of different successional states. Several studies have attempted to link variability in disturbance to patterns of recovery (Dayton 1971, Sousa 1979a, 1984b, Dayton et al. 1984, 1992, Keough 1984, Farrell 1989, Butler 1991, BenedettiCecchi \& Cinelli 1993, Shumaway \& Bertness 1994). In some instances, such links emerged as interactions among the attributes of the disturbed patches (mainly size) and the effects of the biological processes occurring therein (i.e. competition and predation). For example, the effects of limpets on macroalgae may be more intense in small than in large patches as a result of the greater density of herbivores in the former areas (Suchanek 1978, Sousa 1984b, Farrell 1989). Temporal changes in community structure after disturbance may also be complicated by interactions among the biological processes themselves. The effect of predation on the rate of recovery, for example, may be completely different if the species most affected by consumers facilitate or inhibit the establishment of later colonists (Farrell 1991). Further complexity may arise if early successional species do not have the same effect on a later one (Turner 1983, Breitburg 1985), or if later colonists respond in a different manner from the same early successional species (Breitburg 1984).

In the past, successional changes have been described mainly in terms of competitive interactions among colonists (Connell \& Slatyer 1977). Recently, the importance of timing and intensity of recruitment, in addition to predator-prey interactions, has also been recognized (Hawkins 1981, Hawkins \& Hartnoll 1983, Sousa 1984b, Underwood \& Denley 1984, Menge \& Sutherland 1987, Menge \& Farrell 1989). Of particular relevance, although rarely tested (but see Wootton 1993), is the prediction that variability in timing and intensity of recruitment may affect the outcome of competition. Competitive ability often depends upon the relative size and density of interacting species. Large species tend to constrain small ones through several mechanisms, including overgrowth, bulldozing, sweeping and shading (e.g. Connell 1961, Dayton 1971, 1975, Paine 1977. Buss 1980, Hawkins 1983. Goldberg 1987). In some circumstances, assemblages of early successional species that recruit at high densities can pre-empt colonization of later colonists despite a relative smaller size (Hruby \& Norton 1979, Hawkins 1981, Sousa et al. 1981, Lubchenco 1983, Reed \& Foster 1984). Sessile organisms with spatially and temporally variable patterns of recruitment may, however, inter- act in several combinations of their relative size and density. An obvious implication is that the outcome of competition may be reversed in situations where size and density are positively correlated with competitive ability. The possibility for competitive reversals may have important consequences for the dynamics of succession, injecting additional variability in the temporal sequence (Wootton 1993).

In this paper we focus on disturbance and recovery in littoral rock pools dominated by macroalgae. Rock pools are discrete, patchy habitats, structured by a complex set of physical and biological factors. Previous investigations have concentrated on seasonal changes and zonation and patterns have been related either to abiotic factors such as temperature, $\mathrm{pH}$ and time of submergence and emergence (Gustavsson 1972, Femino \& Mathieson 1980, Sze 1980, 1982), or to biological processes such as predation and competition (Dethier 1982, Lubchenco 1982, Chapman 1990, Metaxas \& Scheibling 1993). Only one study has considered the role of disturbance in rock pools (Dethier 1984). This contrasts with the relatively rich body of literature available for emergent rocky intertidal communities (see Sousa 1985 and references therein). The probable cause of this discrepancy, besides historical reasons, is that the great variability existing among and within pools makes experimental analyses difficult and complex (Dethier 1982, 1984, Astles 1993).

Here, patterns of disturbance and recovery have been studied following the general protocol recommended (but rarely adopted) by Sousa (1984b) and Foster \& Sousa (1985). We (1) examined the effects of disturbance by monitoring the size distributions of patches of open space (mainly consisting of patches of encrusting corallines and bare rock) in pools exposed to natural and reduced densities of herbivores; (2) carried out a multifactorial experiment testing for the effects of herbivores, location, size and time of formation of patch on patterns of recovery in artificially cleared plots; and (3) manipulated the abundance of algal turfs to test for their effects on the development of canopy-forming species (Cystoseira spp.). In a previous study (Benedetti-Cecchi \& Cinelli 1992a), we investigated the effects of resident mats of algal turfs on the establishment of Cystoseira. Here, we have examined the effects of algal turfs on Cystoseira during succession.

\section{MATERIALS AND METHODS}

The study system. Algal mosaics dominating littoral rock pools on the west coast of Italy (western Mediterranean) have received some attention in recent years (Benedetti-Cecchi \& Cinelli 1.992a, b). Briefly, the sys- 
tem is composed of stands of canopy-forming species (Cystoseira brachicarpa var. balearica and C. compressa) interspersed among patches of turfing algae (mainly Corallina elongata, Halopteris scoparia and Padina pavonica) and encrusting corallines (mainly Lithothamnion sp.). Filamentous algae (Cladophora rupestris, Polysiphonia spp. and Sphacelaria spp.) also occur as epiphytes on the other plants or as early successional species in recently disturbed gaps. For the purpose of this study such algae are not included in the turf-forming group, but are considered as a separate category. Potential sources of disturbance are waves, wave-driven rocks and herbivores. Such disturbances may remove erect organisms from the substratum exposing the underlying encrusting algae and, to a lesser extent, bare rock.

Both adult-adult and adult-juvenile interactions play an important role in determining patterns of species distribution and abundance in this system. Experimental studies (Benedetti-Cecchi \& Cinelli 1992a, b) indicate that an adult canopy of Cystoseira may inhibit recruitment of its juveniles and the development of algal turfs. These, in turn, strongly depress the recruitment of Cystoseira. This suggests that the outcome of competition may be determined by the life history stages of the interacting species, rather than by species identity.

Grazing is also important in the system although previous investigations considered only short-term effects (Benedetti-Cecchi \& Cinelli 1992a). The most common herbivores are limpets (Patella aspera and P. caerulea) and the sea urchin Paracentrotus lividus. Limpets may reduce the abundance of filamentous algae and germlings of Cystoseira, but they have no apparent impact on large and structurally complex thalli. This suggests that Patella can delay but not prevent colonization by large plants if these have the chance to escape from grazing during the early stages of development. Finally, the overall effect of sea urchins on the distribution and abundance of macroalgae in littoral rock pools seems to be of minor importance. These herbivores, in fact, spend much of their time in crevices probably in response to light that can be intense in these shallow habitats. As a consequence, grazing by sea urchins is evident mainly in narrow areas just in front of their refuges (Benedetti-Cecchi \& Cinelli 1995).

This study was carried out on the exposed rocky shore south of Livorno, Italy $\left(43^{\circ} 30^{\prime} \mathrm{N}, 10^{\circ} 20^{\prime} \mathrm{E}\right)$ from February 1991 to November 1993. Eighteen pools distributed along $2 \mathrm{~km}$ of coast were used for observations and experiments (Fig 1). Pools ranged in size from about 4 to $12 \mathrm{~m}^{2}$ (50 to $100 \mathrm{~cm}$ deep) and were located from 0.1 to $0.3 \mathrm{~m}$ above the mean low level water. Because of their location on the shore, these pools
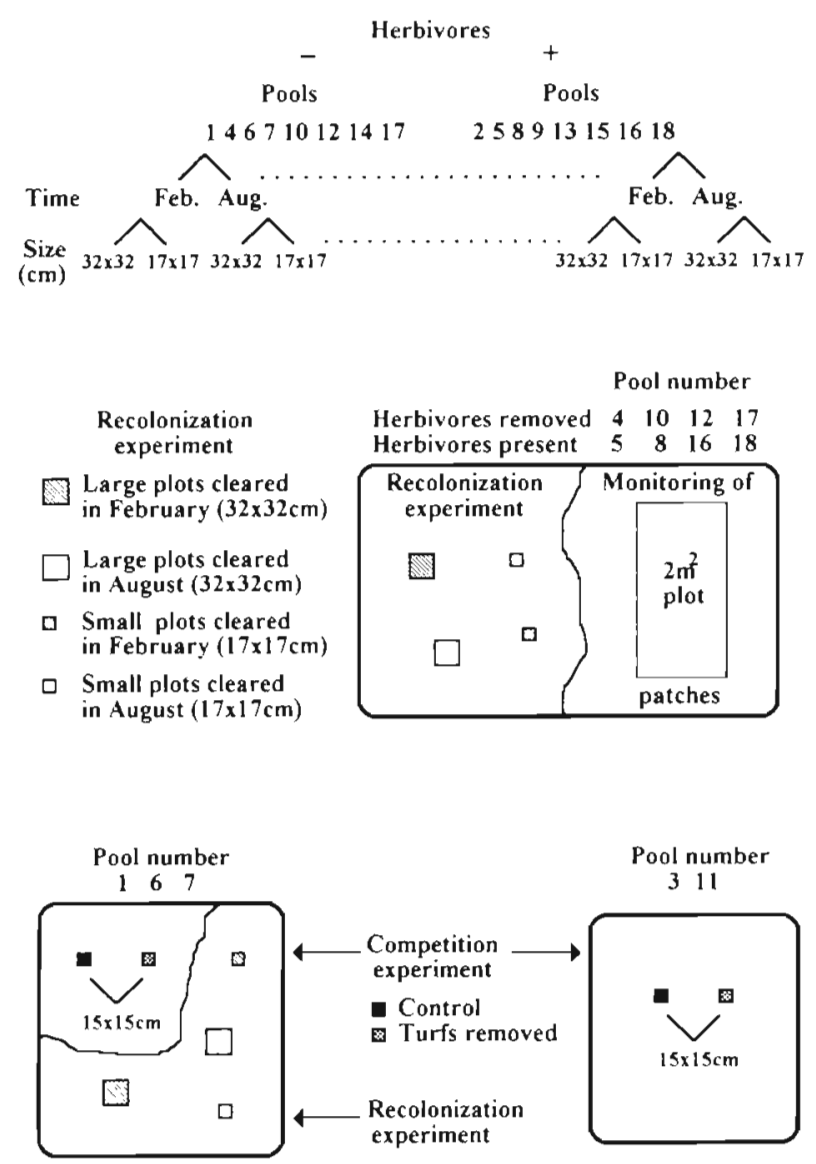

Fig. 1. Schematic diagrams illustrating (A) the design of the recolonization experiment, $(B)$ one of the large pools used in both the recolonization and disturbance experiments and (C) the 2 types of pools employed to investigate the effects of algal turfs on Cystoseira spp Pools were numbered starting from the southern part of the study area and moving north

were flooded by sea water even during calm sea conditions. This could have reduced the importance of physiological stress due to environmental fluctuations on algal and animal populations (but sea urchins could be an exception), particularly in comparison with high shore pools.

Monitoring of patches of open space. We define a patch of open space as a discrete area deprived of erect macroalgae (including with this term also the tufts of filamentous algae) bordered by stands of algal turfs or Cystoseira spp. Many of these gaps were dominated by encrusting corallines which, in most cases, were not continuous in coverage therefore exposing the underlying bare rock. Although bare rock and encrusting algae may be not equivalent with respect to settlement of algal propagules, they represent potential sites for colonization by erect plants. We have assumed that the patches of open space described above reîlecied iìle occurrence of recent disturbance events producing gaps in an otherwise continuous stand of erect algae. 
We have also assumed that these patches could be maintained by additional disturbances inhibiting or delaying algal recovery. With these assumptions in mind, we monitored the size distributions of patches of open space in 8 large pools chosen at random along the shore. The corners of eight $2 \times 1 \mathrm{~m}$ permanent plots (1 for each pool) were marked with pieces of epoxy putty (Subcoat S, Veneziani, Italy) at the beginning of the study. All the patches occurring in these plots were censused seasonally from February 1991 to February 1993 and their sizes recorded. Approximate estimates of areas were obtained by measuring the 2 major axes of each gap (Paine \& Levin 1981). Gaps with very irregular borders were decomposed in sub-patches approximating more regular geometric figures (in general rectangles). The total surface of a given patch was then calculated by adding up the area of each subpatch. This approach produced reliable estimates of the true size of patches (Benedetti-Cecchi \& Cineili 1992C). The importance of limpets and sea urchins as sources of biological disturbance was determined by hand removal of these herbivores (see below) from 4 out of 8 pools chosen at random. All limpets present in the $2 \mathrm{~m}^{2}$ plots were counted during each census, while the density of sea urchins was assessed in two $1 \mathrm{~m}^{2}$ plots chosen at random in each pool.

Recolonization experiment. A multifactorial experiment tested for the effect of herbivores, size and time of formation of patch on algal recovery in artificially cleared plots. Sixteen pools were employed in this experiment, 8 of which also contained the $2 \mathrm{~m}^{2}$ plots used in the monitoring program described above (see Fig. 1). Such pools were sufficiently large to keep the 2 study areas 1.5 to $2 \mathrm{~m}$ apart. Four experimental units, consisting of 2 large $(32 \times 32 \mathrm{~cm})$ and 2 small $(17 \times$ $17 \mathrm{~cm}$ ) quadrats, were randomly distributed in each pool in areas densely covered by erect macroalgae. These sizes were within the range of those produced by natural disturbance (see 'Results: Monitoring of patches of open space'). Two plots (1 large and 1 small quadrat) were cleared in February 1991 and the other 2 in August 1991. Treatments were assigned to the experimental units at random. The corners of each plot were marked with the epoxy putty for subsequent relocation. Erect algae were removed with a paint scraper and a plastic brush, while encrusting corallines (including the bases of Corallina elongata) remained attached to the rock. Also the holdfasts of Cystoseira spp. were carefully searched in the quadrats and removed, while fragments of the prostrate thalli of very small algae (e.g. Gelidium spp.) might have gone undetected. The experimental plots did not differ macroscopically from natural patches of open space and were intended to mimic the effects of intense perturbations. The effect of herbivores on recovery was as- sessed by removal of limpets and sea urchins from 4 additional pools, chosen at random among the 8 not employed in the monitoring of disturbance (hence there were 8 pools exposed to natural grazing pressure and 8 pools maintained at reduced densities of herbivores). Visits every 4 wk were sufficient to effectively reduce the abundance of grazers (see 'Results: Recolonization experiment').

The abundance of macroalgae was assessed every 2 or 3 mo from February 1991 to August 1993. A surface of $100 \mathrm{~cm}^{2}$ was sampled in the centre of each plot using plexiglas sheets (either $17 \times 17 \mathrm{~cm}$ or $32 \times 32 \mathrm{~cm}$ depending on the size of patches) with 100 equally spaced dots. The plexiglas sheets were placed over the pieces of epoxy putty that marked the corners of each experimental unit. The projected cover of a particular algal group was assessed by counting the number of dots lying over the target organisms. When different algal groups were found at a single intercept point (particularly late in the study), both overstory and understory organisms were sampled. This procedure was possible because epiphytes did not completely obscure their host and canopy species could be moved aside leaving the underlying vegetation visible to the observer. Conversely, the total cover of erect macroalgae (see 'Results: Recolonization experiment') was assessed by subtracting the percentage of open space (as defined in the previous section) from 100. The density of limpets was evaluated by counting the number of individuals in whole plots, while the density of sea urchins was determined in two $1 \mathrm{~m}^{2}$ quadrats chosen at random in each experimental pool (as already indicated).

Analysis of variance (ANOVA) was used to test for the effects of treatments on patterns of algal colonization, with herbivores, size of patches and time of clearance as fixed, orthogonal factors and pools nested in herbivores as a random effect. Four dates were analysed for each algal group in a successional sequence at intervals of 3 to $9 \mathrm{mo}$. Three criteria determined which dates had to be analysed in each sequence. First, they should span the range from early to late successional stages, relative to the temporal scale considered in this study. Second, assumptions for parametric analyses (see below) should be met. Third, no more than 4 dates for each algal group had to be analysed because of increasing risk of Type I errors.

Because of the lack of replication of treatments within pools there is no estimation of the error variance and tests for the significance of random effects (pools nested in herbivores and the first and second order interactions with size of patches and time of clearance) are not possible with these analyses. As a consequence we have to assume that the higher order interaction 
term Size $\times$ Time $\times$ Pools (Herbivores) is not significant. If this is not true, there are no hypotheses related to the other terms in the model.

The effects of treatments on the density of limpets were analysed using ANOVAs for randomized block designs, with pools treated as blocks and size of patches and time of clearance as fixed, orthogonal factors. The Tukey's test for non-additivity (Winer 1971. Underwood 1981) was used to exclude interactions between treatments and blocks (although only a particular form of non-additivity is accounted for by this test).

Cochran's test was used throughout the study to check for homogeneity of variances (Winer 1971). When necessary, percent cover values were arcsine transformed, while the logarithmic transformation was used for the density of limpets. Plots of residuals were also examined to check for strong deviations from normality (Sokal \& Rohlf 1981).

It was of interest in the context of this study (see 'Discussion: Patterns of recolonization') to see whether there was sufficient power to detect a significant effect of herbivores on Cystoseira if the impact occurring late in succession had been as large as that observed at the recruit stage. Results from previous investigations (see Benedetti-Cecchi \& Cinelli 1992a) were used to determine this effect. Power was calculated using tables and formulas provided by Cohen (1988). An alpha value of 0.05 was used for this calculation.

Effects of algal turfs on Cystoseira spp. Finally, 10 additional quadrats $(15 \times 15 \mathrm{~cm})$ were marked in 5 pools ( 3 of which were also used in the previous experiment, see Fig. 1) to test for the effect of algal turfs on the establishment of Cystoseira during succession. In order to avoid confusion among competitive and predator-prey interactions, only pools maintained at reduced densities of herbivores were used in this experiment. The experimental units were cleared of erect organisms as described above and were randomly assigned to treatments and controls ( 1 treatment and 1 control were matched in each pool). Treatments consisted of quadrats kept free of algal turfs, while controls were left undisturbed after initiation. Algal turfs were selectively removed from treatment areas every $4 \mathrm{wk}$ using forceps. Care was taken not to scrape the substratum when removing the turfs, thus avoiding artifacts due to the accidental removal of recently settled embryos of Cystoseira. This experiment started in June 1992 during the main settlement period of Cystoseira (Benedetti-Cecchi \& Cinelli 1992a) and ended in November 1993. A surface of $100 \mathrm{~cm}^{2}$ was sampled every $2 \mathrm{mn}$ in the centre of each plot using the technique described above. Care was taken to maintain consistent accuracy in the sampling method across treatments.
The overall effect of removal of algal turfs was estimated by ANOVA on the slopes of the lines obtained by regressing the abundance of Cystoseira spp. in each plot over time. ANOVA for randomized block designs was used with pools as blocks, after Tukey's test for non-additivity. Analyses were also done to see whether there was sufficient power to detect a significant result if the impact of the algal turfs on Cystoseira during succession had been as large as that determined by resident mats of turfing plants (see Benedetti-Cecchi \& Cinelli 1992a).

\section{RESULTS}

\section{Monitoring of patches of open space}

Natural densities of sea urchins ranged from $8 \pm 2.9$ to $21 \pm 6.3$ ind. $\mathrm{m}^{-2}$ (means $\pm 1 \mathrm{SE}, \mathrm{n}=16$ ) with no evident seasonal trends (test diameters ranged from 1.5 to $7 \mathrm{~cm}$ ). In contrast, densities fluctuated from $0.75 \pm 0.25$ to $3.4 \pm 0.7$ ind $\mathrm{m}^{-2}$ in pools where grazers were periodically removed. Overall, the mean number of sea urchins occurring in these areas, expressed as a percentage of number found in control pools (no manipulation of herbivores) at each sampling date, was $11.3 \pm$ $1.4 \%$ (mean $\pm 1 \mathrm{SE}, \mathrm{n}=11$ ). Total exclusion was not achieved because sea urchins reinvaded removal areas by migrating from adjacent pools and from the subtidal, and also by recruiting from the plankton ( $L$. Benedetti-Cecchi pers, obs.). Further details of the spatial and temporal patterns of the distribution of Paracentrotus lividus in rock pools have been reported in a separate paper (Benedetti-Cecchi \& Cinelli 1995). Natural densities of Patella spp. in the $2 \mathrm{~m}^{2}$ plots ranged from $26 \pm 8.9$ to $39.3 \pm 16$ ind. $2 \mathrm{~m}^{-2}$ (means $\pm 1 \mathrm{SE}, \mathrm{n}=4$ ). In contrast, densities fluctuated from $1.14 \pm 0.4$ to $9.6 \pm 4.3$ ind $2 \mathrm{~m}^{-2}$ in pools where grazing pressure was reduced experimentally [15.6 $\pm 3.2 \%$ (mean $\pm 1 \mathrm{SE}, \mathrm{n}=7$ ) the number found in natural pools]. Immigrants were new recruits and adults invading from nearby emergent substrates. These herbivores concentrated in patches of open space and were never seen climbing over the erect macroalgae. Their size ranged from 0.5 to $2.8 \mathrm{~cm}$.

At the beginning of the study, the percentage of open space (means $\pm 1 \mathrm{SE}, \mathrm{n}=4$ ) was $18.3 \pm 3.5 \%$ and $14.6 \pm 5.8 \%$ in control and treatment pools, respectively. Similar values were obtained at the end of the monitoring period (February 1993). At that time, the percentage of cleared space was $19.8 \pm 4.7 \%$ in pools exposed to natural densities of herbivores, and $11.7 \pm$ $2.9 \%$ in pools where grazers had been removed. D̄îferences among treatment and control pools were not significant ( $p>0.05$, Student's $t$-test) 
Only size distributions of patches monitored during the winter season are presented here (Fig. 2). Seasonal changes were not evident, although the area of open space due to patches larger than $600 \mathrm{~cm}^{2}$ declined during summer. This trend was mainly due to the seasonal bloom of filamentous algae. During the warm season, filamentous species rapidly colonized patches of bare rock and encrusting corallines that were no longer monitored as disturbed areas until the next autumn, when the cover of ephemeral algae declined (see also Benedetti-Cecchi \& Cinelli 1992a). Given the difficulty in ascertaining whether or not these fluctuations reflected variability in disturbance (see 'Discussion: Measuring disturbance'), only data collected in winter were compared. Size distributions shifted slightly

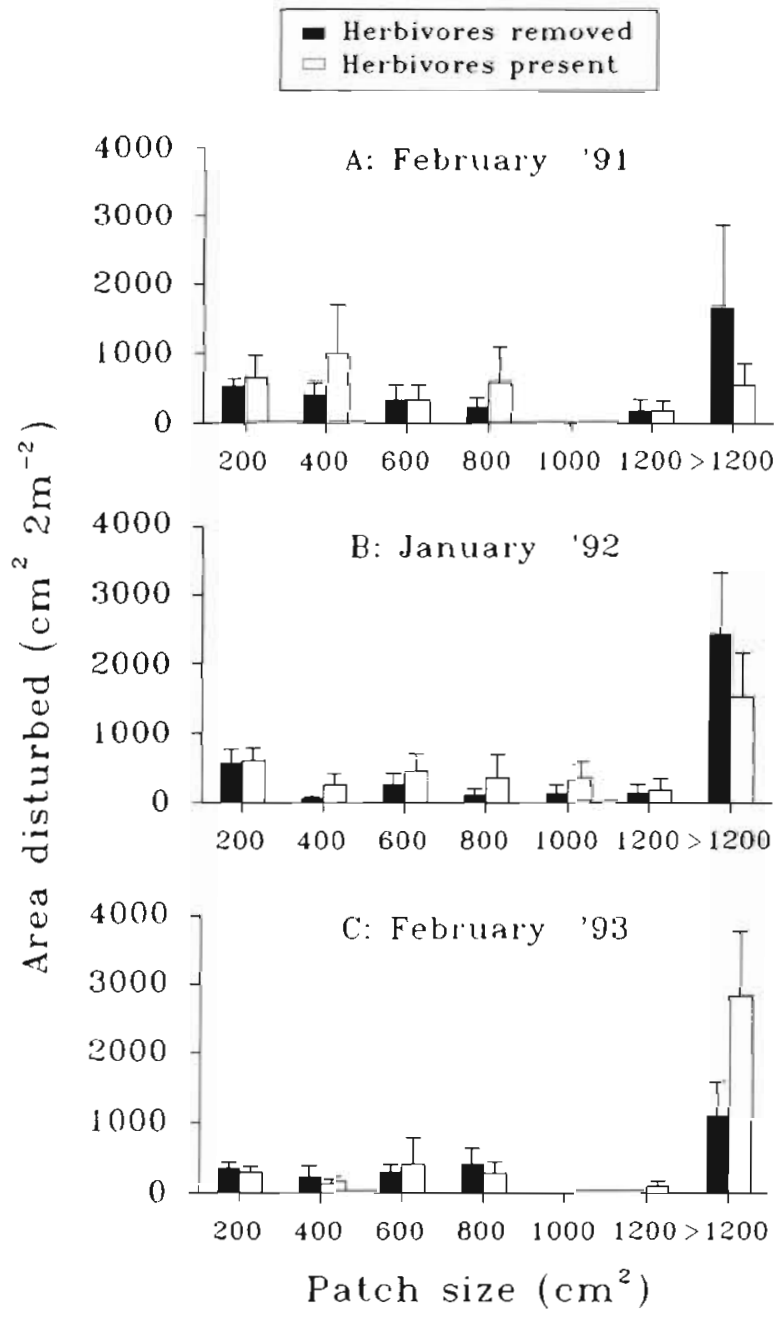

Fig. 2. Size distributions of patches of open space in pools exposed to normal (open bars) and reduced (filled bars) densities of herbivores. Data represent the total area of open space (means $+1 \mathrm{SE}, \mathrm{n}=4$ ) accounted for by each size class. Values on the $x$-axis represent the upper limits of the size classes (with the exception of the largest class, for which the lower limit is indicated) towards larger classes from 1991 to 1993 in natural pools (no manipulation of herbivores), but not in those where the density of grazers was reduced. The area accounted for by large size-classes $\left(>1200 \mathrm{~cm}^{2}\right)$ showed inverse temporal trends, increasing in pools with natural densities of herbivores and decreasing in the others. However, grazing never affected size distributions significantly $(p>0.05$ for all years, Kolmogorov-Smirnov test; data from the 4 replicated pools in each treatment were pooled for the analyses).

\section{Recolonization experiment}

Manipulation of herbivores effectively excluded limpets (Patella spp.) from the experimental clearings. Only a few recruits were found in areas where grazing pressure was reduced and they were readily removed. In contrast, limpets invaded the artificial patches soon after the start of the experiment in pools where herbivores were not manipulated. Natural abundances of limpets (means $\pm 1 \mathrm{SE}, \mathrm{n}=8$ ) ranged from a minimum of $0.38 \pm 0.18$ ind. $225 \mathrm{~cm}^{-2}$ in June 1991 (small patches produced in winter), to a maximum of $2.4 \pm 0.65$ ind $225 \mathrm{~cm}^{-2}$ in February 1992 (small patches produced in summer; Fig. 3). These grazers were more abundant in the patches produced in August than in those cleared in February during the first 6 mo of experimentation (Fig. 3). A significant effect $\left(F_{1,7}=7.24, p=0.031\right)$ due to the time of clearance was found for 6 mo old patches.

\section{Limpets}

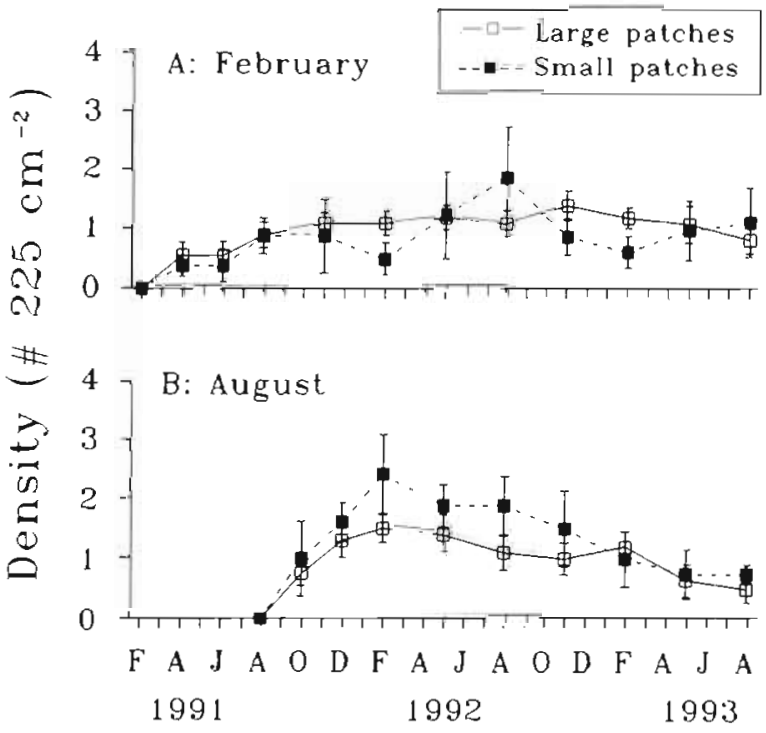

Fig. 3. Effects of size and time of formation of patch on the abundance of Impets. Values are mean $( \pm 1 \mathrm{SE}, \mathrm{n}=8)$ untransformed densities in large $\square$ and small - plots produced in (A) February and (B) August 1993 
After that time, densities in the former areas declined progressively to converge towards those observed in the latter ones (Fig. 3). However, a significant size $x$ time of clearance interaction was found after 12 mo from the start of the experiment $\left(F_{1,7}=10.55, \mathrm{p}=0.014\right)$. This resulted because the large patches cleared in winter supported greater densities of Patella spp. than the small ones produced in the same season, while the opposite was true for the patches cleared in summer These patterns were no longer evident for the other dates analysed (18 and 24 mo old patches; Fig. 3) Finally, the distribution of Patella spp. among pools was homogeneous (Tukey's test not significant).

There were large differences in the effects of the experimental treatments on the total cover of erect macroalgae during the early stages of colonization, as opposite to the patterns observed late in the study (Fig. 4). The rate of recovery was greater in quadrats cleared in summer than in winter, particularly for the first 2 mo of succession. During that period, differences were also evident among the large and small patches cleared in winter and maintained at reduced densities of herbivores, with large clearings supporting greater cover of macroalgae. This pattern was not evident for plots produced in summer (Fig. 4). There were significant size $\times$ time of clearance interactions after 6 and 12 mo of recovery (Table 1). These resulted because the small patches cleared in winter supported greater algal cover than the large ones produced in the same season, while the reverse occurred for the experimental areas initiated in summer (Fig. 4). These patterns were no longer evident after 21 and 24 mo of recovery (Table 1). The removal of grazers significantly increased the total cover of erect algae, independently from the time of clearance and the size of patches (Fig. 4, Table 1).

Patterns of abundance of filamentous aigae in cleared plots were highly seasonal. Cover values peaked during the warm season in all years and were consistent among treatments (Fig. 5). There was a significant size $\times$ time of clearance interaction after 4 mo of recovery (Table 2 ). This resulted because the filamentous algae were more abundant in the small than in the large patches when treatments were initiated in February, while the opposite was true when patches were cleared in August (Fig. 5). Time as a main factor was significant after 12,21 and 24 mo (Table 2). It is worth noting that these effects reflected mainly seasonal peaks in algal abundance, rather than differences due to the time of clearance per se. For example, after 12 and 14 mo from start the filamentous algae were more abundant in the patches cleared in August than in those produced in February, while the reverse occurred for 21 mo old patches. The impact of herbivores was variable and a significant effect was found after 21 mo of recovery.

There were some differences in the abundance of Cystoseira spp. among patches produced at different

\section{Total cover of erect macroalgae}

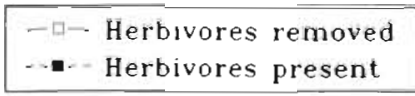

\section{A: Large-February}

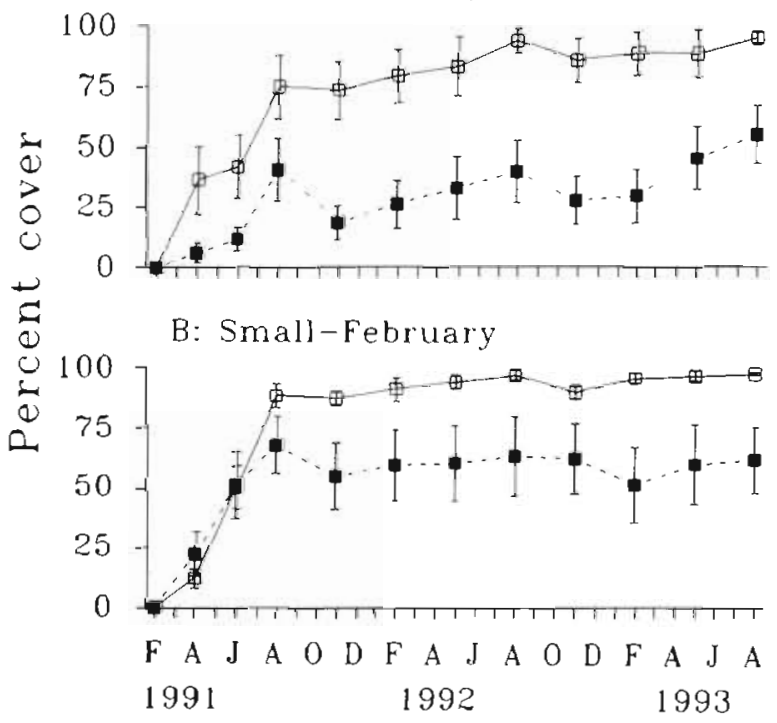

C: Large-August

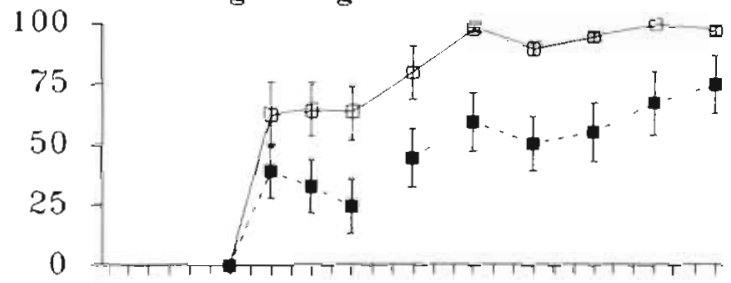

D: Small-August

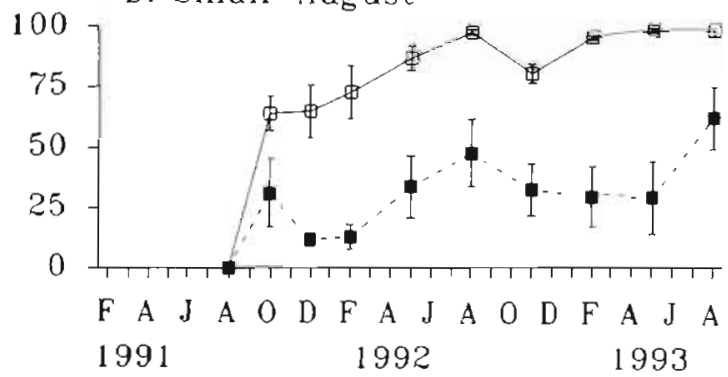

Fig. 4. Effects of herbivores, size and time of formation of patch on the total cover of erect macroalgae. Values are mean $( \pm 1$ SE, $\mathrm{n}=8$ ) untransformed percent covers from (A) large and (B) small plots produced in February 1991, and from (C) large and (D) small plots produced in August 1991 
Table 1. Detaled analysis of variance for the effects of fixed factors on the total cover of enect macroalgae. Effects of Herbivores $[\mathrm{H}]$ were tested over the Pools(Herbivores) $[=\mathrm{P}(\mathrm{H})]$ mean square, the effects of Size $[=\mathrm{S}]$ and Herbivores $\times$ Size were tested over the Sixe $\times$ Pools(Herbivores) mean square, the effects of Time [= T] and Herbivores $\times$ Time were tested over the Time $\times$ Pools $($ Herbivores) mean square, and the interactions Size $\times$ Time and Herbivores $\times$ Size $\times$ Time were tested over the Size $\times$ Time $\times$ Pools(fierbivores) mean square. Bold numbers indicate significance $(p<0.05)$

\begin{tabular}{|c|c|c|c|c|c|c|c|c|c|c|c|c|c|}
\hline \multirow{2}{*}{$\begin{array}{l}\text { Source of } \\
\text { variation }\end{array}$} & \multirow[t]{2}{*}{$\mathrm{df}$} & & & & \multicolumn{6}{|c|}{ Age of patches (mo) } & \multirow{2}{*}{ MS } & \multirow{2}{*}{$\begin{array}{r}-24 \\
F\end{array}$} & \multirow[b]{2}{*}{$\mathrm{p}$} \\
\hline & & MS & $F$ & $\mathrm{p}$ & MS & $F$ & $\mathrm{p}$ & MS & $F$ & p & & & \\
\hline Herbivores & 1 & 9264 & 6.54 & 0.0228 & 11262 & 6.55 & 0.0227 & 11209 & 6.53 & 0.0229 & 3.320 & 12.72 & 0.0031 \\
\hline Size & 1 & 1444 & 8.75 & 0.0104 & 21 & 0.02 & 0.8858 & 123 & 0.15 & 0.7085 & 0.000 & 0.00 & 0.9639 \\
\hline Tine & 1 & 132 & 0.11 & 0.7413 & $j 99$ & 0.15 & 0.7016 & 1269 & 1.03 & 0.3283 & 0.298 & 1.51 & 0.2390 \\
\hline $\mathrm{H} \times \mathrm{S}$ & 1 & 203 & 1.23 & 0.2859 & 365 & 0.37 & 0.5550 & 112 & 0.13 & 0.7210 & 0.188 & 2.06 & 0.1730 \\
\hline $\mathrm{H} \times \mathrm{T}$ & 1 & 1701 & 1.46 & 0.2470 & 192 & 0.15 & 0.7066 & 489 & 0.40 & 0.5394 & 0.074 & 0.38 & 0.5491 \\
\hline $\mathrm{S} \times \mathrm{T}$ & 1 & 3481 & 8.35 & 0.0119 & 4675 & 6.47 & 0.0234 & 2364 & 2.92 & 0.1096 & 0.068 & 0.37 & 0.5546 \\
\hline $\mathrm{H} \times \mathrm{S} \times \mathrm{T}$ & 1 & 798 & 1.92 & 0.1880 & 511 & 0.71 & 0.4140 & 2437 & 3.01 & 0.1047 & 0.051 & 0.27 & 0.6084 \\
\hline Pools $(\mathrm{H})$ & 14 & 1417 & & & 1720 & & & 1717 & & & 0.261 & & \\
\hline $\mathrm{S} \times \mathrm{P}(\mathrm{H})$ & 14 & 164 & & & 1000 & & & 850 & & & 0.091 & & \\
\hline $\mathrm{T} \times \mathrm{P}(\mathrm{H})$ & 14 & 1165 & & & 1304 & & & 1237 & & & 0.197 & & \\
\hline $\mathrm{S} \times \mathrm{T} \times \mathrm{P}(\mathrm{H})$ & 14 & 416 & & & 722 & & & 810 & & & 0.186 & & \\
\hline \multirow{2}{*}{\multicolumn{2}{|c|}{$\begin{array}{l}\text { Cochran's C-test: } \\
\text { Transformation: }\end{array}$}} & \multirow{2}{*}{\multicolumn{3}{|c|}{$C=0.19, p>0.05$}} & \multirow{2}{*}{\multicolumn{3}{|c|}{$C=0.27, \mathrm{p}>0.05$}} & \multirow{2}{*}{\multicolumn{3}{|c|}{$\begin{array}{c}C=0.21, p>0.05 \\
\text { None }\end{array}$}} & \multirow{2}{*}{\multicolumn{3}{|c|}{$\begin{array}{c}C=0.30, \mathrm{p}>0.05 \\
\text { Anqular }\end{array}$}} \\
\hline & & & & & & None & & & & & & & \\
\hline
\end{tabular}

times of the year (Fig. 6). After 4 mo of recolonization these algae were still absent from the patches cleared in February, while after 18 mo Cystoseira spp. was more abundant in these clearings than in those produced in August (Fig. 6, Table 2). Herbivores greatly reduced the cover of these algae during the early stages of colonization and highly significant effects were found after 9 and $12 \mathrm{mo}$ from the start of the experiment (Table 2) In contrast, the impact of herbivores was less evident late in succession (Fig, 6) and no significant effects were found after 18 and 24 mo from start (Table 2). Results from power analysis indicated that if the removal of grazers had produced an increase in the abundance of Cystoseira of the same magnitude as that observed at the recruit stage (which was of the order of $278 \%$ of the control mean; see Benedetti-Cecchi \& Cinelli 1992a), the probability of finding a significant result for the last sampling date analysed would have been high $(81.1 \%)$. Therefore, the impact of grazers on Cystoseira late in succession was not as
Filamentous algae

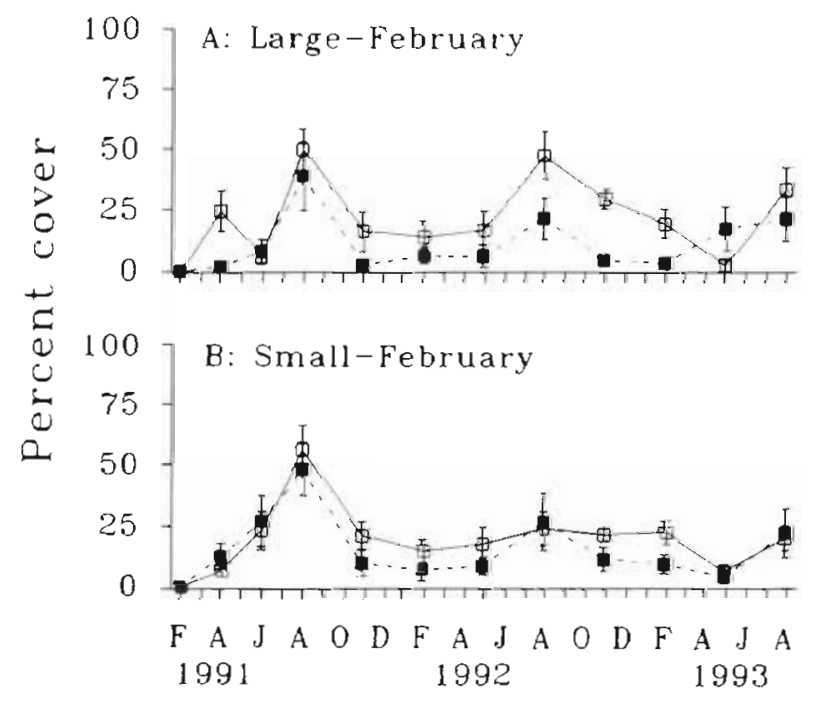

$-\square-$ Herbivores removed --Herbivores present
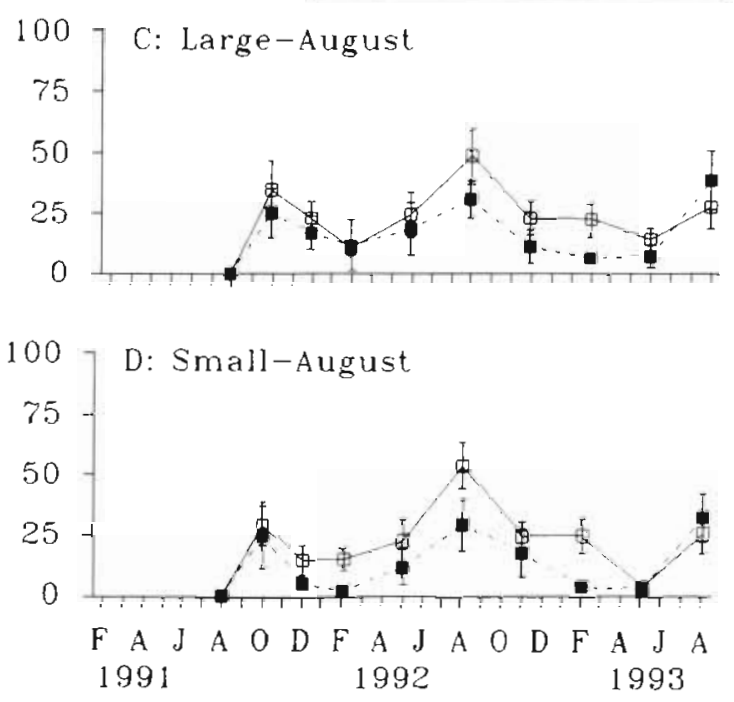

Fig. 5. Effects of herbivores, size and time of formation of patch on filamentous algae. Values are mean $( \pm 1 S E, n=8)$ untransformed percent covers. Other details as in Fig. 4 
Table 2. Summary of results of ANOVAs on different algal groups. Only the effects that have been found significant at least once are included here. H: herbivores; S: size; T: time. Variances were homogeneous (Cochran's C-test); angular transformation was used when appropriate. Violation of this assumption prevented analyses at regular intervals for all the groups. Bold numbers indicate significance $(p<0.05)$

\begin{tabular}{|c|c|c|c|c|c|c|c|c|c|c|c|}
\hline \multicolumn{4}{|c|}{ Filamentous algae } & \multicolumn{4}{|c|}{ Cystoseira spp. } & \multicolumn{4}{|c|}{ Algal turfs } \\
\hline $\begin{array}{l}\text { Source of } \\
\text { variation }\end{array}$ & $\begin{array}{l}\text { Age of } \\
\text { patches }\end{array}$ & $F$ & $\mathrm{p}$ & $\begin{array}{l}\text { Source of } \\
\text { variation }\end{array}$ & $\begin{array}{l}\text { Age of } \\
\text { patches }\end{array}$ & $F$ & p & $\begin{array}{l}\text { Source of } \\
\text { variation }\end{array}$ & $\begin{array}{l}\text { Age of } \\
\text { patches }\end{array}$ & $F$ & p \\
\hline \multirow[t]{4}{*}{$\mathrm{H}$} & 4 & 0.31 & 0.5887 & \multirow[t]{4}{*}{$\mathrm{H}$} & 9 & 17.26 & 0.0010 & \multirow[t]{4}{*}{$H$} & 6 & 6.54 & 0.0228 \\
\hline & 12 & 3.62 & 0.0777 & & 12 & 10.44 & 0.0060 & & 12 & 6.55 & 0.0227 \\
\hline & 21 & 18.46 & 0.0007 & & 18 & 1.03 & 0.3278 & & 18 & 10.62 & 0.0057 \\
\hline & 24 & 0.44 & 0.5202 & & 24 & 2.87 & 0.1121 & & 24 & 12.27 & 0.0035 \\
\hline \multirow[t]{4}{*}{$T$} & 4 & 0.05 & 0.8339 & \multirow[t]{4}{*}{$\mathrm{T}$} & 9 & 0.38 & 0.5452 & \multirow[t]{4}{*}{ S } & 6 & 8.75 & 0.0104 \\
\hline & 12 & 43.55 & 0.0001 & & 12 & 2.36 & 0.1471 & & 12 & 0.02 & 0.8858 \\
\hline & 21 & 17.37 & 0.0009 & & 18 & 4.96 & 0.0428 & & 18 & 0.73 & 0.4070 \\
\hline & 24 & 8.32 & 0.0120 & & 24 & 0.48 & 0.5011 & & 24 & 0.00 & 0.9589 \\
\hline \multirow[t]{4}{*}{$S \times T$} & 4 & 9.88 & 0.0072 & & & & & \multirow[t]{4}{*}{$\mathrm{S} \times \mathrm{T}$} & 6 & 8.35 & 0.0119 \\
\hline & 12 & 0.00 & 0.6778 & & & & & & 12 & 6.47 & 0.0234 \\
\hline & 21 & 1.96 & 0.1834 & & & & & & 18 & 1.99 & 0.1804 \\
\hline & 24 & 1.85 & 0.1950 & & & & & & 24 & 0.42 & 0.5278 \\
\hline
\end{tabular}

large as that occurring during the early stages of colonization. Also, the effect of herbivores was always negligible in the small patches produced in February (Fig. 6B), although no interactions between herbivores and size of patches have been found.

Herbivores, size of patches and time of clearance all affected the patterns of recolonization of the turfing algae (Fig. 7). Significant negative effects of grazers were found for all the dates analysed (Table 2). Significant interactions between size of patches and time of clearance were also found after 6 and 12 mo of recovery (Table 2 ). These patterns resulted because the

\section{Cystoseira spp.}

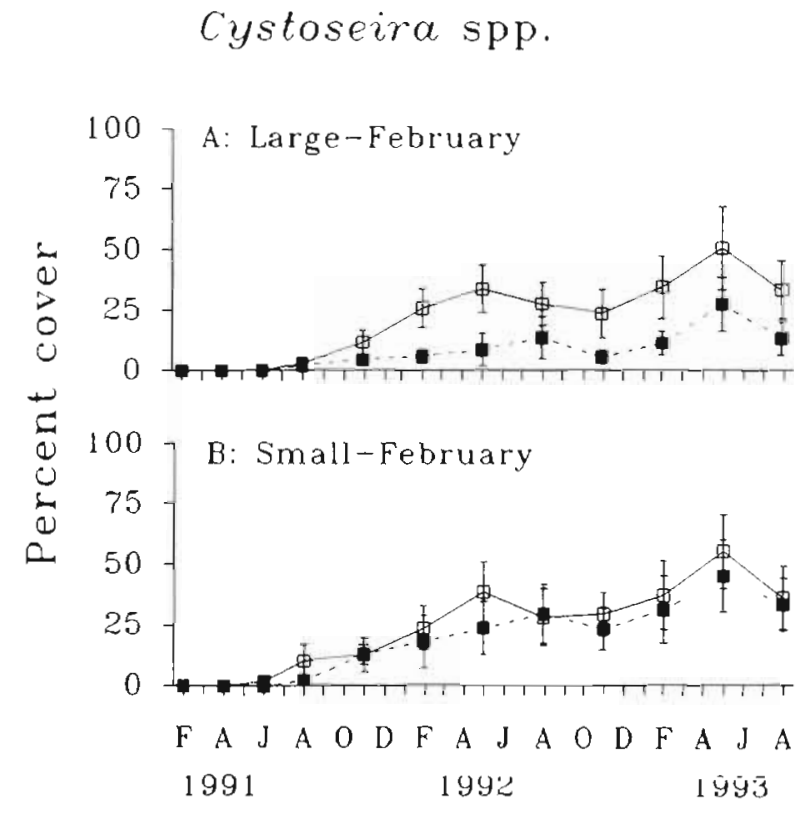

small patches supported greater cover of turfing algae than the large ones if the time of clearance was February, while the reverse occurred if the patches were produced in August (Fig. 7)

By the end of the study, most of the plots maintained at reduced densities of herbivores were dominated by Cystoseira spp. or algal turfs and only few (6 out of 32 , $18 \%$ ) did not exhibit a clear pattern of dominance (Fig. 8A). These outcomes were apparently unrelated to the size of patches and time of clearance. In contrast, plots exposed to natural grazing became dominated by a single group of algae on only a few occasions

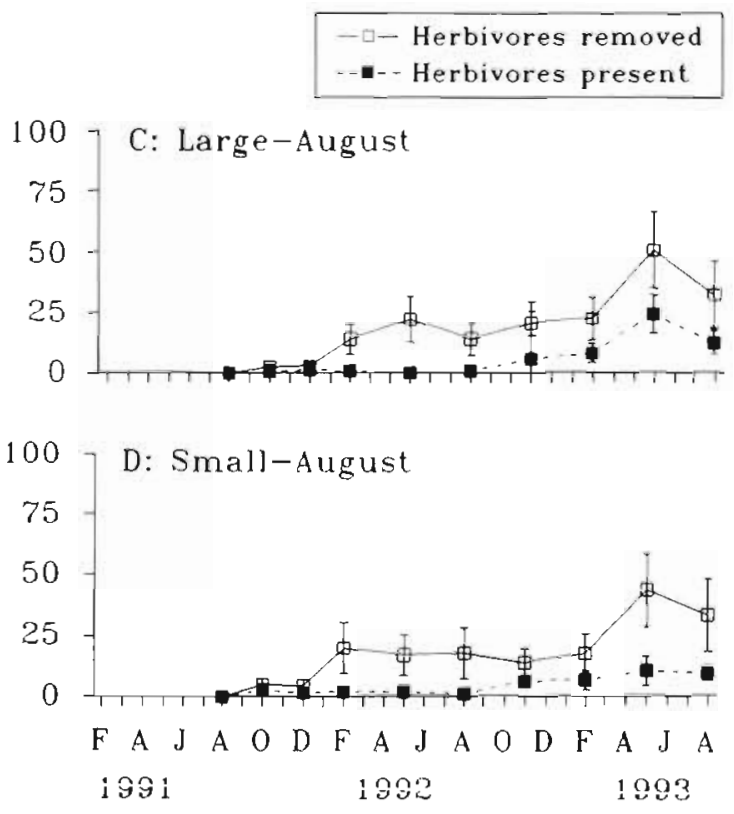

Fig. 6. Effects of herbivores, size and time of formation of patch on Cystoseira spp. Values are mean $( \pm 1$ SE, $n=8)$ untransformed percent covers. Other details as in Fig. 4 
Algal turfs
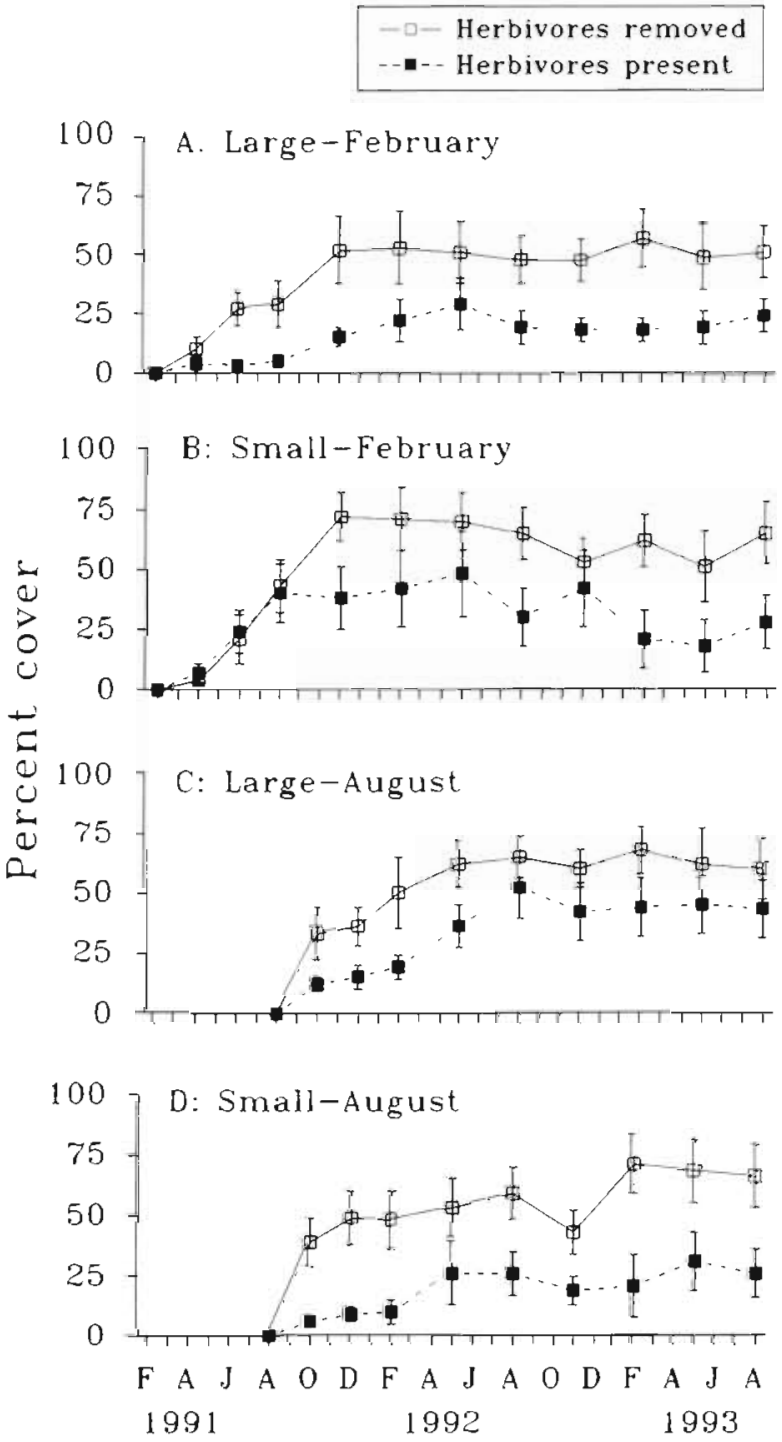

Fig. 7. Effects of herbivores, size and time of formation of patch on turfing algae. Values are mean $( \pm 1 S E, n=8)$ untransformed percent covers. Other details as in Fig. 4

(Fig. 8B). Trajectories of individual patches through time (e.g. Fig. 9) indicated that Cystoseira spp. and algal turfs rarely occurred as mixed stands in patches where grazing was reduced.

\section{Effect of algal turfs on Cystoseira spp.}

Algal turfs did not have any effect on Cystoseira spp during succession (Fig. 10). The former species colonized both treatment and control areas soon after the start of the experiment. In control plots, percent cover values (means $\pm 1 \mathrm{SE}, \mathrm{n}=5$ ) ranged from a minimum of $21 \pm 5.5 \%$ in November 1992 to a maximum of $49 \pm$
A: Herbivores removed

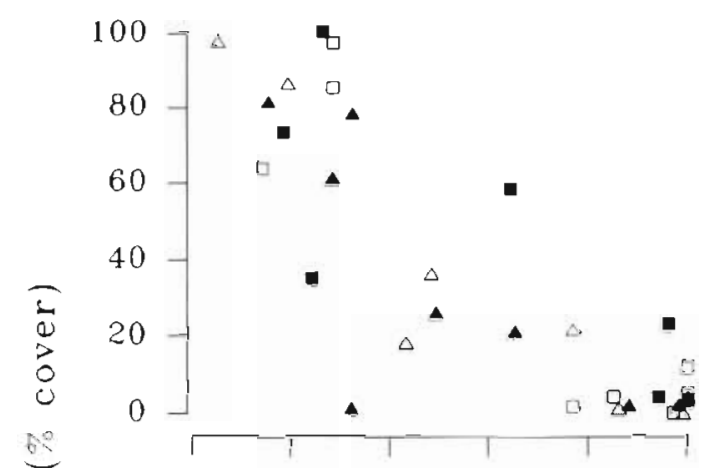

- $32 \times 32$ February

$\triangle 32 \times 32$ August

- $17 \times 17$ February

- $17 \times 17$ August

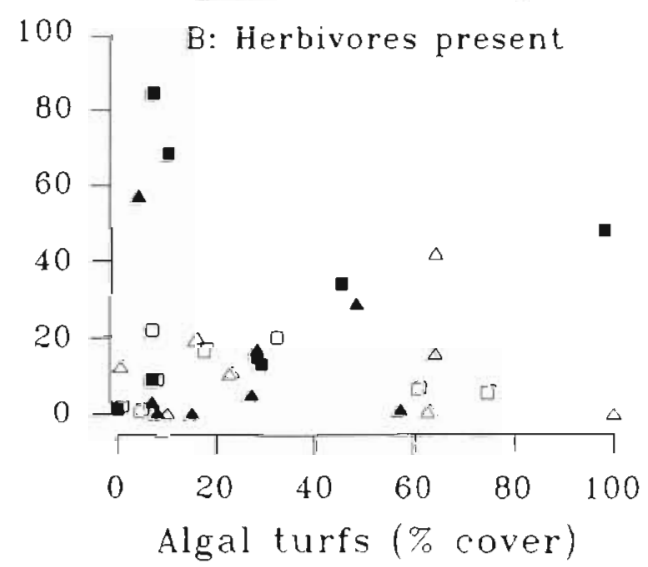

Fig. 8. Abundances of Cystoseira spp. and algal turfs in the experimental patches by the end of the study (August 1993)

$15 \%$ in September 1992 (the first sampling date), but without any evident seasonal trend. Monthly visits were sufficient to keep treatments free from algal turfs. Cystoseira spp. also recruited in all treatment and control plots (the experiment was initiated during the main settlement period of Cystoseira), although patterns of abundance were variable among pools. In general, percent cover values were somewhat higher in the areas cleared of algal turfs, but temporal trends in treatments and controls converged towards similar points. Overall differences were not significant, as indicated by the ANOVA on the slopes obtained by regressing the abundance of Cystoseira spp. in each plot over time $\left(F_{1,4}=1.3, \mathrm{p}>0.05\right)$. However, if the effect of the algal turfs during succession had been the same as that exerted by resident mats (which determined a reduction in the recruitment of Cystoseira of the order of $124 \%$ of the control mean; see BenedettiCecchi \& Cinelli 1992a) the probability of detecting a 
Fig. 9. Trajectories of the abundance of Cystoseira spp. and algal turfs in individual patches. Data are from the small patches cleared in August 1991 and maintained at reduced densities of herbivores. Values are untransformed percent covers
A: Pool

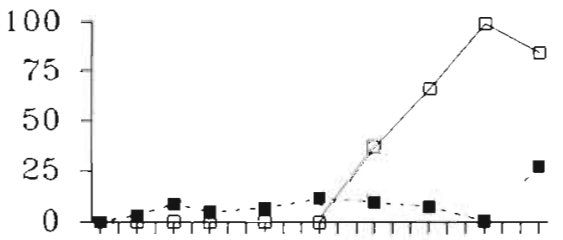

C: Pool 6

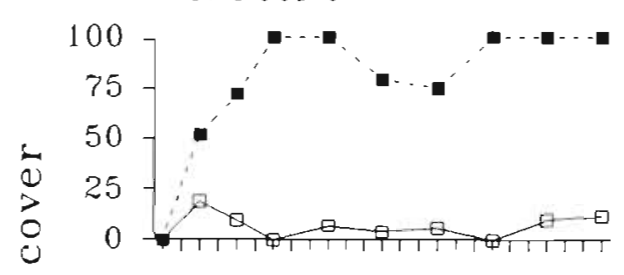

E: Pool 10

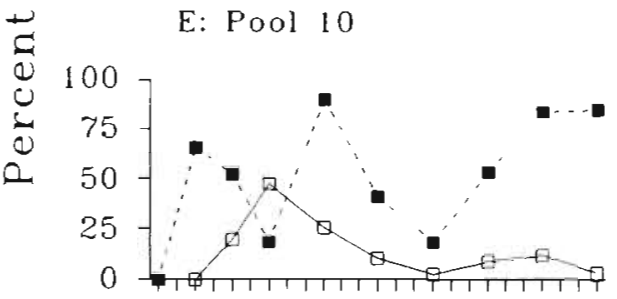

G: Pool 14

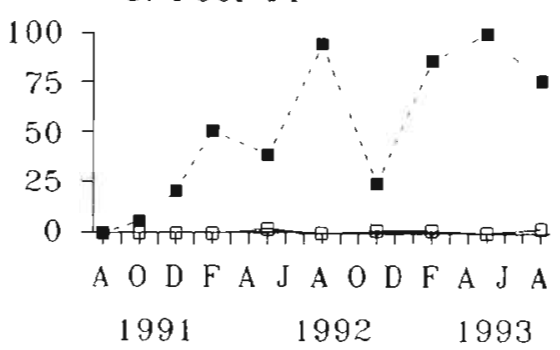

B: Pool 4

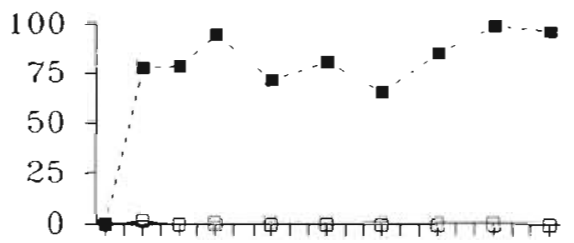

D: Pool 7

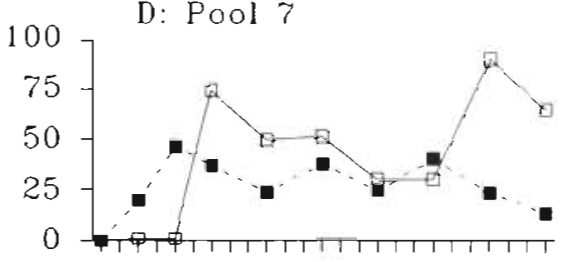

F: Pool 12

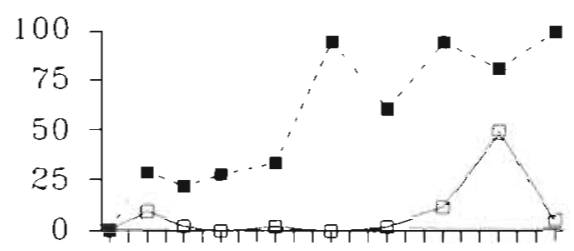

H: Pool 17

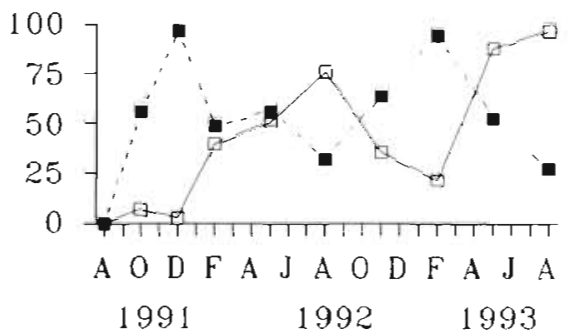

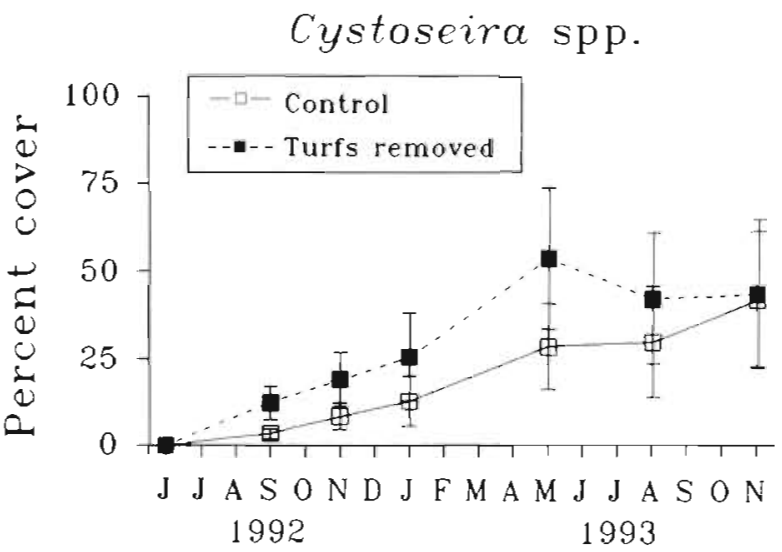

Fig. 10. Effects of algal turfs on Cystoseira spp. Values are mean ( $\pm 1 \mathrm{SE}, \mathrm{n}=5$ ) untransformed percent covers significant result would have been very high (99\%). In contrast, significant differences occurred among pools $\left(F_{4,4}=29.4, \mathrm{p}<0.0032\right)$.

\section{DISCUSSION}

\section{Measuring disturbance}

Claims about the need of quantifying the rate of disturbance to which assemblages of species are exposed and the lack of such information for many natural systems are common in the literature (Spruqel 1976. Dethier 1984, Sousa 1984a, 1985, Pickett \& White 1985 , McGuinness 1987). Nevertheless, only a few papers have provided quantitative data on this aspect of com- 
munity ecology in recent years (e.g. Farrell 1989). This deficiency might reflect in part the difficulty of finding an objective and unambiguous way to measure disturbance in the field. Two main approaches, underlying different definitions of disturbance, have been used in marine benthic systems: (1) quantification of events representing potential sources of mortality for organisms, such as overturning and burial in sand of rocks in intertidal boulder fields (Sousa 1979a, b, 1980, McGuinness 1987), and (2) measurements based on the reduction of percent cover of species or increases of bare space (Paine \& Levin 1981, Dethier 1984, Farrell 1989). The former approach provides estimates of the frequency and intensity of disturbance that are independent of the response of organisms. Therefore, such estimates are not necessarily an expression of the effects of natural perturbations on communities. McGuinness (1987), for instance, found that large rocks were overturned and buried less than small ones, but the total cover of sessile species was not related to the size of the rocks. Although some differences in species composition and abundance existed among large and small boulders, this could be related to the different proportion of propagules 'sampled' by these rocks from the water column as a consequence of their relative surface area (McGuinness 1987). These results contrast with those reported for a similar habitat by Sousa (1979a, b, 1980). This author found that the percent of open space was greater for boulders of small size, a pattern consistent with the high frequency of disturbance affecting these rocks.

The second approach involves direct measurements of abundances of organisms. Dethier (1984), for example, in her study of disturbance and recovery in intertidal rock pools, defined disturbance as a loss of biomass exceeding $10 \%$ cover of a sessile species within a period of less than 6 mo. Farrell (1989), working in an intertidal community on the Oregon coast (USA), quantified the rate of disturbance by monitoring the number and size distribution of patches of bare space in fixed plots over a period of $9 \mathrm{mo}$. A similar approach was also used in our investigation. The major problem with this method is difficulty in discriminating between variability in disturbance and seasonal changes in species abundance. Further complications arise if the 2 processes are not independent. For example, the seasonal blooms of filamentous algae observed in this study determined the reduction of the area of cleared space accounted for patches larger than $600 \mathrm{~cm}^{2}$ during the summer, but it was impossible to assess if these patterns reflected a reduced rate of disturbance, seasonal fluctuations in physico-chemical parameters (for example light intensity and availability of nutrients), or the interplay among these factors.
Despite the limitations discussed above, size distributions of cleared gaps are important to assess the actual range of sizes available to colonists, and then to plan field studies where the effects of disturbance are simulated by the artificial removal of organisms. In addition, the areal extent of patches of open space may be adopted as the response variable in experimental investigations of disturbance (e.g. Sousa 1980). In the present study, we have examined the role played by limpets and sea urchins in the formation of such areas. Although the importance of large clearings $\left(>1200 \mathrm{~cm}^{2}\right)$ decreased in pools where herbivores had been removed, neither size distributions nor the total area of open space were affected significantly by manipulation of grazers. McGuinness (1987) considered the differences existing between physical disturbances and biological processes such as grazing and predation, and pointed out the importance of distinguishing among them. Apparently, the provision of open space in the rock pools south of Livorno was mainly due to physical perturbations, particularly storms, which may be severe in any period of the year at this exposed location (see also Benedetti-Cecchi \& Cinelli 1995). With the exception of limpets and sea urchins, there was no other herbivore in the system potentially capable of scraping the substratum in such a way as to produce a patch (L. Benedetti-Cecchi pers. obs.). In addition, sea urchins were found to exert very little effects on assemblages of erect algae 50 to $60 \mathrm{~cm}$ far from their refuges in this system (Benedetti-Cecchi $\&$ Cinelli 1995). Therefore, constraints on foraging behaviour might have limited the role of sea urchins in the production of patches of open space. The lack of significant effects due to herbivores, however, must be viewed with caution because of the low number of replicate pools.

In synthesis, the 2 approaches discussed above focus on different aspects of disturbance and both of them may result in ambiguous estimates of the effects of perturbations on organisms. The choice of one or the other should depend on the system investigated, the hypotheses tested and the operational definition of disturbance adopted. The integration of the 2 approaches, where possible, would be the best way to quantify perturbations in natural communities and their interplay with biological processes.

\section{Patterns of recolonization}

The results show that herbivores, size of patches and time of clearance exerted important but variable effects on patterns of algal recovery in artificially cleared areas. There were significant size $\times$ time of clearance interactions affecting either the total cover 
of erect macroalgae or the abundance of the filamentous and turfing plants, but these effects were important mainly during the early stages of colonization. In contrast, at later stages there were significant differences between pools for all the algal groups analysed. Herbivores greatly reduced the rate of succession in the experimental patches. Both the total cover of erect macroalgae and the abundance of the turfing plants were significantly affected by herbivores late in the study. Conversely, the impact of grazers on Cystoseira spp. decreased as succession proceeded.

The size of patches and the time of clearance can have significant effects on patterns of species recovery (Bazzaz 1979, Sousa 1984a, 1985). Time of clearance also affects the specific composition of the early successional assemblage and this may result in strong priority effects (Egler 1954, Dean \& Hurd 1980, Robinson \& Dickerson 1987). Patch size may determine the relative importance of vegetative propagation and sexual recruitment as mechanisms of colonization (Sousa 1984b, Farrell 1989) and of long-distance versus short-distance dispersal (Keough 1984, Brokaw 1985). In addition, it may also affect growth conditions of organisms. In terrestrial systems, seedling emergence and diversity is greater in large patches due to a greater availability of resources (Bazzaz 1979, Phillips \& Shure 1990). In highly stressful habitats, such as salt marshes, the size of patches can affect the mechanism of succession. For example, Shumaway \& Bertness (1994 and references therein) reported that facilitatory mechanisms were responsible for successional changes in large patches, while succession was driven by competitive interactions in small areas where physical conditions were less severe. Indirect effects due to the size of patches were also found on emergent substrata in rocky-shore systems. Sousa (1984b) found marked differences in patterns of recovery between small and large patches and these differences resulted as a consequence of the greater abundance of limpets in the former areas.

The differences due to the time of clearance observed in this study must be viewed with caution. Although the experiment was initiated either in summer or in winter, there was only a single date for each season and there was no way to unconfound seasonal effects from intrinsic differences among dates (i.e. there should have been some random dates of initiation of the experiment in both winter and summer). A similar problem was also discussed by Underwood \& Anderson (1994). However, the small patches supported greater algal cover than the large ones at early stages, but only if clearings were nroduced in February. In addition, these patterns were more evident in pools exposed to natural densities of grazers, suggesting that size and time of formation of gaps could affect algal abundance indirectly by influencing primarily the distribution of herbivores. Although no significant interactions between herbivores and size and/or time of clearance were found early in the study, the distribution of limpets in the experimental patches was partially consistent with the observed patterns of algal abundance. In fact, the density of Patella spp. was significantly lower in the plots cleared in winter than in those produced in summer after 6 mo from start. However, factors other than grazing must be invoked to explain the differences in algal cover between the large and small plots cleared in February, as the abundance of limpets was very similar in these areas. A possible alternative would be that recolonization occurred more quickly in small than in large quadrats as a result of lateral encroachment of algae from the borders (Sousa 1985, Farrell 1989). However, patterns of recovery did not differ consistently between the edge and central zones of these areas during the first 18 mo of succession (L. Benedetti-Cecchi unpubl. data). This suggested that vegetative propagation was unimportant in determining differences among the large and small patches. Also, peripheral grazing probably was not important in these areas, as there were no differences in the density of limpets between the central and marginal zones of the patches (L. Benedetti-Cecchi unpubl. data). Therefore, other models must be considered to explain the results discussed above and further research is necessary to clarify these points.

The role of herbivores in affecting patterns of succession has been largely explored in both terrestrial (Cates \& Orians 1975, Walker et al. 1986, De Steven 1991) and marine systems (e.g. Sousa 1985, Farrell 1991). Grazers often appear to forage more heavily on early successional species in both systems and their effect on the rate of succession may depend on the strength of competitive interactions between early and late colonists (Farrell 1991). A number of studies have reported a negative effect of grazers on the abundance and distribution of algae in littoral rock pools (Paine \& Vadas 1969, Lubchenco 1978, 1982, Dethier 1982, 1984, Underwood \& Jernakoff 1984, Chapman 1989, Arrontes \& Underwood 1991; but see Chapman 1990). The results reported here are consistent with those of the literature: algal abundance was greatly reduced in patches exposed to natural densities of herbivores and the resulting patterns of succession were delayed in comparison with those occurring in plots where grazers had been removed. Although no attempt was made to separate the effect of limpets from that of sea urchins, the former organisms were likely to play a major role in regulating patterns of succession. In fact, the experimental patches were made within stands of erect algae which, as also discussed in the previous section (see 'Results: Measuring disturbance'), were 
probably out of the range of activity of sea urchins. A limited effect of herbivores as efficient as sea urchins could explain why the establishment of macroalgae was reduced but not totally depressed by grazing. For instance, the impact on Cystoseira, which was strong during the early stages of colonization (BenedettiCecchi \& Cinelli 1992a, this study), was not significant after 2 yr of succession. Results from power analysis indicated that the chance to detect an effect of grazers as large as that observed at the recruit stage was high $(81.1 \%)$, highlighting the biological relevance of the pattern. Possibly, Cystoseira spp. could escape the impact of grazers (limpets) by attaining a refuge in size and/or by chemical defences (see also BenedettiCecchi \& Cinelli 1992a). An implication of this is that herbivores might confer some advantages to Cystoseira with respect to other algae more exposed to the impact of grazers late in succession. Below we discuss in some detail the relative importance of herbivory versus competitive interactions in affecting patterns of algal distribution and dominance in the experimental patches.

\section{Nonhierarchical competition, herbivory, and the outcome of succession}

There was more than one single outcome of succession in this study. Patterns of algal dominance were clear in the patches maintained at reduced densities of herbivores by the end of the experiment. Many of these plots were dominated ( $>50 \%$ in coverage, see Dethier 1984) by Cystoseira spp. or by the turfing algae and a few of them did not exhibit a clear pattern. Also, these outcomes were unrelated to initial effects due to the size of patches or time of clearance, as there was no apparent correlation between algal abundance and experimental treatments by the end of the study (Fig. 8A). In contrast, only a few of the patches exposed to natural densities of herbivores were dominated by Cystoseira or turfing algae in August 1993 (Fig. 8B). These patterns suggested that competitive interactions could have affected the abundance and distribution of Cystoseira and algal turfs in areas where grazing was unimportant. Previous investigations showed that the percent cover of turfing algae increased significantly after the removal of Cystoseira, suggesting a competitive superiority of the latter organisms (BenedettiCecchi \& Cinelli 1992a, b). However, dense 'mats' of turfing plants drastically inhibited the recruitment of Cystoseira, indicating that pre-emption of the substratum could limit the performance of canopy-forming algae in littoral rock pools (Benedetti-Cecchi \& Cinelli 1992a). Additional insights into the dynamics of these interactions were also provided by this study, showing that algal turfs did not exert any strong effect on Cystoseira when the 2 groups of algae recruited at the same time. Overall, these results suggested that competition among the turfing and canopy-forming species was nonhierarchical, the outcome of the interaction depending primarily upon the relative density and life stage of the interacting organisms, rather than on their identity.

The effects at both the population and community level of competitive reversals and nonhierarchical competitive networks have been explored mainly in animal-dominated communities, including larval anuran assemblages (Alford \& Wilbur 1985, Lawler \& Morin 1993), coral reefs (Buss \& Jackson 1979) and mussel beds (Wootton 1993). Body size is one of the most likely mechanisms of competitive reversal in these systems and size asymmetries between interacting organisms may depend on the historical details of community development (e.g. Drake 1991). The present results suggest that colonization and competitive events can be important factors for the maintenance of plant mosaics in littoral rock pools. The nonhierarchical nature of the competitive interaction among the algal turfs and Cystoseira could provide a trade-off among initial variability in timing and intensity of recruitment (i.e. variability in the order and abundance by which species colonized the experimental plots) and patterns of algal dominance. Succession would have led to the dominance of Cystoseira when recruitment by this genus was antecedent to, or synchronous with, that of turfing species. In contrast, the algal turfs would have persisted as dominant species in patches where they monopolized the substratum (bare rock and encrusting corallines) before the arrival of Cystoseira. Observations of trajectories of individual patches partially supported this view (e.g. Fig. 9).

It is worth noting that the interactions among turfing and canopy-forming algae appeared important only in areas where grazing pressure was reduced. As indicated earlier, by the end of the study there were no clear patterns of algal dominance in patches exposed to natural densities of consumers (Fig. 8B). There are 2 important implications of this. First, herbivores had the potential to break the inhibitory effect exerted by turfing algae on Cystoseira, therefore increasing the rate of recovery by canopy-forming species if these could escape from grazing (e.g. Farrell 1991). This indirect interaction may have injected additional variability in the dynamics of succession and prolonged the coexistence of Cystoseira and algal turfs in the same gaps. Second, factors other than competition and predation could have played an important role in determining patterns of community structure and dynamics in areas where algal recruitment was not plentiful. Previous work has indicated that patterns in 
mature communities may be determined directly by the initial supply of settlers when populations are not regulated by density dependent mechanisms (Connell 1985, Gaines \& Roughgarden 1985, Lewin 1986, Roughgarden et al. 1988, Underwood \& Fairweather 1989, Raimondi 1990, Sutherland 1990). In these circumstances, knowledge of the processes affecting the transport, settlement and early life stages of larvae or algal propagules is crucial to the understanding of patterns of community organization. The contributions of these factors and that of indirect interactions to the structure and dynamics of algal assemblages in discrete, patchy habitats such as littoral rock pools remain to be investigated.

Acknowledgements. We thank F. Boero, S. Bonotto, A. R. O. Chapman, M. S. Foster, S. D. Gaines, S. J. Hawkins, R. T Paine, R. Scheibling and an anonymous reviewer for helpful comments on early versions of the manuscript. We also thank A. J Underwood for suggestions and criticism on some of the statistical analyses reported here. Stefano Acunto, Marco Castellazzi and Sergio Genovesi provided excellent field and technical assistance. This work is part of a Ph.D. thesis by L.B.-C. and was supported by a MURST $60 \%$ project to F.C.

\section{LITERATURE CITED}

Alford RA, Wilbur HM (1985) Priority effects in experimental pond communities: competition between Bufo and Rana. Ecology 66:1097-1105

Arrontes J, Underwood AJ (1991) Experimental studies on some aspects of the feeding ecology of the intertidal starfish Patiriella exigua. J Exp Mar Biol Ecol 148:255-269

Astles KL (1993) Patterns of abundance and distribution of species in intertıdal rock pools. J Mar Biol Ass UK 73: $555-569$

Bazzaz FA (1979) The physiological ecology of plant succession. A Rev Ecol Syst 10:351-371

Benedetti-Cecchi L, Cinelli F (1992a) Effects of canopy cover, herbivores and substratum type on patterns of Cystoseira spp. settlement and recruitment in littoral rockpools. Mar Ecol Prog Ser 90:183-191

Benedetti-Cecchi L, Cinelli F (1992b) Canopy removal experiments in Cystoseira-dominated rockpools from the Western Coast of the Mediterranean (Ligurian Sea). J Exp Mar Biol Ecol 155:69-83

Benedetti-Cecchi L, Cinelli F (1992c) Patch monitoring as a field method to quantify natural disturbance in hard bottom communities. Rapp P-v Réun Commn Int Explor Scient Mer Méditerr 23:30

Benedetti-Cecchi L, Cinelli F (1993) Early patterns of algal succession in a midlittoral community of the Mediterranean sea: a multifactorial experiment. J Exp Mar Biol Ecol 169:15-31

Benedetti-Cecchi L, Cinelli F (1995) Habitat heterogeneity, sea urchin grazing, and the distribution of algae in littoral rock pools on the west coast of Italy (western Mediterranean). Mar Ecol Prog Ser 126:203-212

Blau WS (1980) The effect of environmental disturbance on a tropical butterfly population. Ecology 61:1005-1012

Breitburg DL (1984) Residual effects of grazing: inhibition of competitor recruitment by encrusting coralline algae. Ecology $65: 1136-1143$
Breitburg DL (1985) Development of a subtidal epibenthic community: factors affecting species composition and the mechanisms of succession. Oecologia 65:173-184

Brokaw NVL (1985) Gap phase regeneration in a tropical forest. Ecology 66:682-687

Buss LW (1980) Competitive intransitivity and size frequency distributions of interacting populations. Proc Natl Acad Sci USA. 77:5355-5359

Buss LW, Jackson JBC (1979) Competitive networks: nontransitive competitive relationships in cryptic coral reef environments. Am Nat 113:223-234

Butler AJ (1991) Effect of patch size on communities of sessile invertebrates in Gulf St. Vincent, south Australia. J Exp Mar Biol Ecol 153:255-280

Cates RG. Orians GH (1975) Successional status and the palatability of plants to generalized herbivores. Ecology $56: 410-418$

Chapman ARO (1989) Abundance of Fucus spiralis and ephemeral seaweeds in a high eulittoral zone: effects of grazers, canopy and substratum type. Mar Biol 102: $565-572$

Chapman ARO (1990) Effects of grazing, canopy cover and substratum type on the abundance of common species of seaweeds inhabiting littoral fringe tide pools. Botanica Mar 33:319-326

Cohen J (1988) Statistical power analysis for the behavioral sciences, 2nd edn. Lawrence Erlbaum, Hillsdale, NJ

Connell JH (1961) The influence of interspecific competition and other factors on the distribution of the barnacle Chthamalus stellatus. Ecology 42:710-723

Connell JH (1985) The consequences of variation in initial settlement vs post-settlement mortality in rocky intertidal communities. J Exp Mar Biol Ecol 93:11-45

Connell JH, Slatyer RO (1977) Mechanisms of succession in natural communities and their role in community stability and organization. Am Nat 111:1119-1143

Dayton PK (1971) Competition, disturbance, and community organization: the provision and subsequent utilization of space in a rocky intertidal community. Ecol Monogr 41 : $351-389$

Dayton PK (1975) Experimental evaluation of ecological dominance in a rocky intertidal algal community. Ecol Monogr $45: 137-159$

Dayton PK, Curril V, Gerrodette T, Keller BD, Rosenthal R, Tresca DV (1984) Patch dynamics and stability of some California kelp communities. Ecol Monogr 54:253-289

Dayton PK, Tegner MJ, Parnell PE, Edwards PB (1992) Temporal and spatial patterns of disturbance and recovery in a kelp forest community. Ecol Monogr 62:421-445

Dean TA, Hurd LE (1980) Development in an estuarine fouling community: the influence of early colonists on later arrivals. Oecologia 46:295-301

De Steven D (1991) Experiments on mechanisms of tree establishment in old-field succession: seedling emergence. Ecology 72:1066-1075

Dethier MN (1982) Pattern and process in tidepool algae: factors influencing seasonality and distribution. Botanica Mar 25:55-66

Dethier MN (1984) Disturbance and recovery in intertidal pools: maintenance of mosaic patterns. Ecol Monogr 54: $99-118$

Drake JA (1991) Community-assembly mechanics and the structure of an experimental species ensemble. Am Nat $13+: 1-26$

Egler FE (1954) Vegetation science concepts. I. Initial floristic composition, a factor in old-field development. Vegetatio 14:412-417 
Farrell TM (1989) Succession in a rocky intertidal community: the importance of disturbance size and position within a disturbed patch. J Exp Mar Biol Ecol 128:57-73

Farrell TM (1991) Models and mechanisms of succession: an example from a rocky intertidal community. Ecol Monogr 61:95-113

Femino RJ, Mathieson AC (1980) Investigations of New England marine algae. IV The ecology and seasonal succession of tide pool algae at Bald Head Cliff, York, Maine, USA. Botanica Mar 23:319-332

Foster MS, Sousa WP (1985) Succession. In: Littler MM, Littler DS (eds) Handbook of phycological methods. Cambridge University Press, Cambridge, p 269-290

Gaines SD, Roughgarden J (1985) Larval settlement rate: a leading determinant of structure in an ecological community of the marine intertidal zone. Proc Natl Acad Sci USA $82: 3707-3711$

Goldberg DE (1987) Neighborhood competition in an oldfield plant community. Ecology 68:1211-1223

Gustavsson U (1972) A proposal for a classification of marine rockpools on the Swedish west coast. Botanica Mar 15: $210-214$

Harper JL (1977) Population biology of plants. Academic Press, New York

Hawkins SJ (1981) The influence of season and barnacles on the algal colonization of Patella vulgata exclusion areas. J Mar Biol Ass UK 61:1-15

Hawkins SJ (1983) Interactions of Patella and macroalgae with settling Semibalanus balanoides (L.). J Exp Mar Biol Ecol 71:55-72

Hawkins SJ, Hartnoll RG (1983) Grazing of intertidal algae by marine invertebrates. Oceanogr Mar Biol A Rev 21 $195-282$

Heinselman HL (1973) Fire in the virgin forests of the Boundary Waters Canoe Area, Minnesota. J Quat Res 3:329-382

Henry JD, Swan JMA (1974) Reconstructing forest history from live and dead plant material - an approach to the study of forest succession in southwest New Hampshire. Ecology 55:772-783

Hruby T, Norton TA (1979) Algal colonization on rocky shores in the Firth of Clyde. J Ecol 67:65-77

Keough MJ (1984) Effects of patch size on the abundance of sessile marine invertebrates. Ecology 65:423-437

Lawler SP, Morin PJ (1993) Temporal overlap, competition, and priority effects in larval anurans. Ecology 74:174-182

Lewin R (1986) Supply-side ecology. Science 234:25-27

Lubchenco J (1978) Plant species diversity in a marine intertidal community: importance of herbivore food preference and algal competitive abilities. Am Nat 112:23-39

Lubchenco $\mathbf{J}$ (1982) Effects of grazers and algal competitors on fucoid colonization in tide pools. J Phycol 18:544-550

Lubchenco J (1983) Littorina and Fucus: effects of herbivores, substratum heterogeneity, and plants escapes during succession. Ecology 64:111.6-1123

McGuinness KA (1987) Disturbance and organisms on boulders. I. Patterns in the environment and the community. Oecologia 71:409-419

Menge BA, Farrell TM (1989) Community structure and interaction webs in shallow marine hard-bottom communities: test of an environmental stress model. Adv Ecol Res 19: $189-262$

Menge BA, Sutherland JP (1987) Community regulation: variation in disturbance, competition, and predation in relation to environmental stress and recruitment. Am Nat 130:730-757

Metaxas A, Scherbling RE (1993) Community structure and organization of tidepools. Mar Ecol Prog Ser 98:187-198
Paine RT (1977) Controlled manipulations in the marine intertidal zone and their contributions to ecological theory. The changing scenes in natural sciences 1776-1976. Acad Natl Sci, Philadelphia, Spec Publ 12:245-270

Paine RT (1979) Disaster, catastrophe and local persistence of the sea palm Postelsia palmaeformis. Science 205:685-687

Paine RT, Levin SA (1981) Intertidal landscapes: disturbance and the dynamics of pattern. Ecol Monogr 51:145-178

Paine RT, Vadas RL (1969) The effects of grazing by sea urchins, Strongylocentrotus spp., on benthic algal populations. Limnol Oceanogr 14:710-719

Phillips DL, Shure DJ (1990) Patch-size effects on early succession in Southern Appalachuan forests. Ecology 71:204-212

Pickett STA, White PS (1985) Natural disturbance and patch dynamics: a synthesis. In: Pickett STA, White PS (eds) The ecology of natural disturbance and patch dynamics. Academic Press, Orlando, FL, p 371-384

Raimond PT (1990) Patterns, mechanisms, consequences of variability in settlement and recruitment of an intertidal barnacle. Ecol Monogr 60:283-309

Reed DC, Foster MS (1984) The effects of canopy shading on algal recruitment and growth in a giant kelp forest. Ecology $65: 937-948$

Robinson JV, Dickerson JE Jr (1987) Does invasion sequence affect community structure? Ecology 68:587-595

Roughgarden J, Gaines S, Possingham. H (1988) Recruitment dynamics in complex life cycles. Science 241: $1460-1466$

Shumaway SW, Bertness MD (1994) Patch size effects on marsh plant secondary succession mechanisms. Ecology 75:564-568

Sokal RR, Rohlt FJ (1981) Biometry. WH Freeman, New York Sousa WP (1979a) Experimental investigations of disturbance and ecological succession in a rocky intertidal community. Ecol Monogr 49:227-254

Sousa WP (1979b) Disturbance in marine intertidal boulder fields: the nonequilibrium maintenance of species diversity. Ecology 60:1225-1239

Sousa WP (1980) The responses of a community to disturbance: the importance of successional age and species' life histories. Oecologia 45:72-81

Sousa WP (1984a) The role of disturbance in natural communities. A Rev Ecol Syst 15:353-391

Sousa WP (1984b) Intertidal mosaics: patch size, propagule availability, and spatiaily variable patterns of succession. Ecology 65:1918-1.935

Sousa WP (1985) Disturbance and patch dynamics on rocky intertidal shores. In: Pickett STA, White PS (eds) The ecology of natural disturbance and patch dynamics. Academic Press, Orlando, FL, p 101-124

Sousa WP, Schroeter SC, Gaines SD (1981) Latitudinal var1ation in intertidal algal community structure: the influence of grazing and vegetative propagation. Oecologia 48 : $297-307$

Sprugel DG (1976) Dynamic structure of wave-generated Abies balsamea forests in the northeastern. United States. J Ecol 64:889-911

Suchanek TH (1978) The ecology of Mytilus edulis L. in exposed rocky intertidal communities. J Exp Mar Bıol Ecol 31:105-120

Suchanek TH (1981) The role of disturbance in the evolution of life history strategies in the intertidal mussels Mytilus edulis and Mytilus californianus. Oecologia 50: $143-152$

Sutherland JP (1990) Recruitment regulates demographic variation in a tropical intertidal barnacle. Ecology 71 . $955-972$ 
Sze P (1980) Aspects of the ecology of macrophytic algae in high rock pools at the Isles of Shoals (USA). Botanica Mar 23:313-318

Sze P (1982) Distribution of macroalgae in tide pools on the New England coast (USA). Botanica Mar 25:269-276

Turner $T$ (1983) Facilitation as a successional mechanism in a rocky intertidal community. Am Nat 121:729-738

Underwood AJ (1981) Techniques of analysis of variance in experimental marine biology and ecology. Oceanogr Mar Biol A Rev 19:513-605

Underwood SJ, Anderson MJ (1994) Seasonal and temporal aspects of recruitment and succession in an intertidal estuarine fouling assemblage. J Mar Biol Ass UK 74:563-584

Underwood AJ, Denley EJ (1984) Paradigms, explanations and generalizations in models for the structure of intertidal communities on rocky shores. In: Strong DR, Simberloff D, Abele LG, Thistle AB (eds) Ecological communities: conceptual issues and the evidence. Princeton University Press, Princeton, NJ, p 151-180

This article was submitted to the editor
Underwood AJ, Fairweather PG (1989) Supply-side ecology and benthic marine assemblages. Trends Ecol Evol (TREE) $4: 16-20$

Underwood AJ, Jernakoff P (1984) The effects of tidal height, wave exposure, seasonality and rock-pools on grazing and the distribution of intertidal macroalgae in New South Wales. J Exp Mar Biol Ecol 75: $71-96$

Walker LR, Zasada JC, Chapin FS III (1986) The role of life history processes in primary succession on an Alaskan floodplain. Ecology 67:1508-1523

Werner PA (1977) Colonization success of a 'biennal' plant species: experimental field studies of species cohabitation and replacement. Ecology 58:840-849

Winer BJ (1971) Statistical principles in experimental designs, 2nd edn. McGraw-Hill, Kogakusha, Tokyo

Wootton JT (1993) Size-dependent competition: effects on the dynamics vs the end point of mussel bed succession. Ecology 74:195-206

Manuscript first received: July 31, 1995

Revised version accepted: November 9, 1995 